Chapter 31

\title{
Protein-Repellent Functionalizable Surfaces Based on Covalently Bonded Phospholipids with Phosphorylcholine Head
}

\author{
Lynda Ferez, ${ }^{1}$ Thierry Thami, ${ }^{1}$ Lara Tauk, ${ }^{1}$ Edefia Akpalo, ${ }^{1}$ \\ Valérie Flaud, ${ }^{2}$ Armagan Kocer, ${ }^{3}$ Jean-Marc Janot, ${ }^{1}$ \\ and Philippe Déjardin ${ }^{*}, 1$
}

1 Institut Européen des Membranes, Université Montpellier 2 (ENSCM, UM2, CNRS), CC047, 2 Place Eugène Bataillon, F-34095 Montpellier Cedex 5, France

${ }^{2}$ XPS Technologique Platform, Institut Charles Gerhardt, Université Montpellier 2, 2 Place Eugène Bataillon, F-34095 Montpellier Cedex 5, France

3Department of Biochemistry, Groningen Biomolecular Sciences and Biotechnology Institute, University of Groningen, Nijenborgh 4, 9747 AG, Groningen, The Netherlands

*E-mail: Philippe.Dejardin@iemm.univ-montp2.fr

\begin{abstract}
Surface anchored poly(methylhydrosiloxane) (PMHS) films $(\approx 10 \mathrm{~nm}-1 \mu \mathrm{m})$ were functionalized with 1,2-dilinoleoylsn-glycero-3-phosphorylcholine (18:2 Cis). The surface was characterized by X-ray photoelectron spectroscopy, contact angle measurements, atomic force microscopy, and scanning electron microscopy. The interface was very hydrophilic and repellent toward avidin, bovine serum albumin, bovine fibrinogen, lysozyme, cytochrome $\mathrm{C}$ and $\alpha$-chymotrypsin at pH 7.4 as observed by quantitative normal scanning confocal fluorescence. The surface is also repellent to liposomes (400 $\mathrm{nm}$ diameter) of L- $\alpha$-phosphatidylcholine (Soy-20\%). Further possibilities of functionalization on the surface remain available owing to the formation of interfacial $\mathrm{SiOH}$ groups.
\end{abstract}




\section{Introduction}

In many biomedical applications, non specific adsorption is a recurrent problem, as neutrality of the interface with respect to biological fluids is required, whereas additional functionalities may be needed on such a neutral background. This situation especially occurs in the design of biosensors. Blocking buffers are proposed in diagnostic kits with for instance albumin $(1,2)$ to reduce non specific adsorption on functionalized surfaces. This corresponds to the usual strategy of production of biosensors. However, two strategies can be considered to create functionalized surfaces: (i) functionalize first the surface and then block the void surface with some inert material, (ii) block first the surface and then add desired functionalities. We are considering in the present work the second strategy by creating first a protein-repellent background surface rich in phosphorylcholine groups over which functionalities can be grafted thereafter.

Several routes were considered to create surfaces with neutral behavior. They can be roughly classified into two categories (3): the first being based on poly(ethylene oxide) -PEO- (4-16), and the second on zwitterionic groups (17-19), especially the phosphorylcholine head. They correspond to the two main classes of available effective protein-repellent surfaces whose main characteristics is their high hydrophilicity $(20)$.

Poly(ethylene glycol) (PEG) and oligo(ethylene glycol) (OEG) have been widely used to resist nonspecific protein adsorption $(4,21)$. Both are able to form a hydration layer via hydrogen bonds. However, as the temperature increases, the strength of these bonds decreases (22). Moreover, in the presence of oxygen and transition metal ions PEG or OEG can decompose (23).

The choice of the zwitterionic phosphorylcholine (PC) head is inspired by the large number of phospholipids bearing that head on the external side of the bilayer membrane of cells (24). PC-phospholipid polymers were developed many years ago by the group of D. Chapman (25-29) and later by others (30). Chemical transformation of the phospholipids was then necessary to obtain first the polymerizable functional group as was the case when individual surface grafting was carried out (31). Other zwitterionic (sulfobetaine; carboxybetaine) materials have been found to exhibit ultralow protein adsorption $(32,33)$ (fibrinogen adsorption $<5 \mathrm{ng} \mathrm{cm}^{-2}$ ). Such an efficiency is due to the zwitterion structure which retains a large amount of water independent of temperature because of hydration via ionic solvation (18). With phosphate and sulfonate zwitterions, the interface is expected to be electrically neutral over a wide $\mathrm{pH}$ range (5-9), whereas carboxy zwitterions offer variations with $\mathrm{pH}$ which can be exploited. High resistance to protein adsorption was observed for surfaces coated with zwitterionic phospholipids (25). It was suggested that in the presence of interfacial high water content the surface contact does not induce significant conformational changes of the protein (34-37).

The availability of 2-methacryloyloxyethyl phosphorylcholine (MPC) monomer, first introduced by the group of $\mathrm{K}$. Ishihara, has resulted in numerous studies with polymers based on this monomer (38-47). Recently the reaction of the monomer with triethoxysilane was carried out to treat titanium alloy (48). Chemistry on existing polymers in polyelectrolyte multilayer applications (49) or 
on hydroxylated gold in studies on leukocyte adhesion (50) allowed to obtain PC side chains.

Besides these different routes to obtaining PC rich interfaces, we looked at the strategy to creating first soft structures aimed at covalent bonding of PC in high density, then to functionalize with PC. Moreover, rather than using small molecules with PC head like in the MPC monomer, we used phospholipids with long fatty chains like in the biological cells. From this point of view, the method has similarities with the Chapman strategy, one noticeable difference being a final interface without carbon-carbon unsaturated bonds.

We consider the building of a poly(methylhydrosiloxane) (PMHS) scaffold which can be viewed as a large reservoir of $\mathrm{SiH}$ functions $(51,52)$. Then 1,2dilinoleoyl-sn-glycero-3-phosphorylcholine (18:2 Cis) bearing double bonds can react by hydrosilylation reaction leading to a PL-PMHS interface. The process is schematically represented in Figure 1 with the phospholipid (PL) structure. Moreover, the side reaction with water produces some silanols which are available for subsequent functionalization over a background of phosphorylcholine groups.

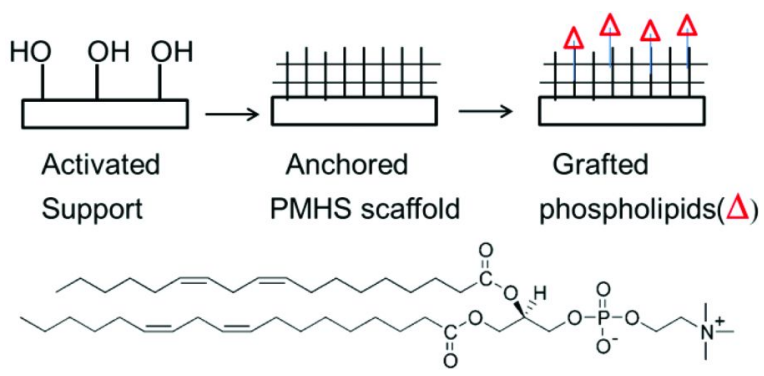

Figure 1. Schematic representation of the successive steps to build an anchored PMHS network functionalized with phospholipids. Structure of 1,2-dilinoleoyl-sn-glycero-3-phosphorylcholine (18:2 Cis).

The present chapter gathers studies performed recently in our laboratory with thick (1 $\mu \mathrm{m}$ order of magnitude) (53) and thin (7-180 nm) layers (54) of PMHS. The protein-repellent character of such surfaces was checked at physiological $\mathrm{pH}$ 7.4 from solutions of bovine serum albumin (BSA), bovine fibrinogen, avidin, $\alpha$-chymotrypsin, cytochrome $\mathrm{C}$ and lysozyme by means of quantitative normal scanning confocal fluorescence. A method of calibration from the solution signal is proposed to extract the interfacial concentration. By the same technique the repellency of such surfaces to liposomes of L- $\alpha$-phosphatidylcholine is also demonstrated.

The presentation is structured in three sections: (i) Materials and methods, (ii) Results and discussion, (iii) Conclusion. The Materials and Methods section has six subsections: chemicals, proteins and labeling, liposome preparation and labeling, methods of preparation of the support, techniques of characterization of the support and finally adsorption: determination of the interfacial concentration. The Results and Discussion section comprises four subsections: material characterization, protein adsorption, liposome adsorption/spreading and finally functionalization of PL-PMHS surface. 


\section{Materials and Methods}

\subsection{Chemicals}

Both precursors methyldiethoxysilane $\mathrm{HSi}\left(\mathrm{CH}_{3}\right)\left(\mathrm{OCH}_{2} \mathrm{CH}_{3}\right)_{2} \quad$ (DH) and triethoxysilane $\mathrm{HSi}\left(\mathrm{OCH}_{2} \mathrm{CH}_{3}\right)_{3}$ (TH) were purchased from ABCR (Karlsruhe, Germany) and used as received. Water for substrate cleaning was obtained from a Milli-Q water purification apparatus (Millipore). Absolute ethanol for sol-gel synthesis was of synthesis grade purity. The sol-gel catalyst trifluoromethanesulfonic acid $\mathrm{CF}_{3} \mathrm{SO}_{3} \mathrm{H}$ was purchased from Aldrich. Toluene for thin film hydrosilylation was distilled before use. The platinum-divinyltetramethyldisiloxane complex in xylene (platinum concentration ca. $0.1 \mathrm{M}$ assuming $2.4 \%$ (w) Pt in xylene), also known as Karstedt's catalyst, was purchased from ABCR (PC072). 1,2-dilinoleoyl-sn-glycero-3-phosphorylcholine (18:2 Cis) (PL) was purchased from AvantiPolarLipids.

Other chemicals were used as received: 3-(ethoxydimethylsilyl)-propyl amine (Aldrich, 588857), Alexa Fluor ${ }^{\circledR} 594$ succinimidyl ester (labelling kit A10239, InvitroGen), biotin-ethylenediamine hydrobromide (Sigma B9181).

\subsection{Proteins and Labeling}

Bovine serum albumin (A-7638), bovine fibrinogen (F-8630), cytochrome C (C-2506), lysozyme (62971-Fluka), $\alpha$-chymotrypsin (C-4129) and avidin (A9275) were purchased from Sigma-Aldrich; some avidin from Fluka (No. 11368). Labeling of proteins was performed with Alexa-fluor-594 succinimidyl ester (InvitroGen, A30008). The procedure of labeling was previously described (53).

\subsection{Liposome Preparation and Labeling}

One hundred milligrams of L- $\alpha$-Phosphatidylcholine (Soy-20\%) (Avanti Polar Lipids Inc. 541601) was dissolved in $5 \mathrm{~mL}$ of chloroform containing $100 \mu \mathrm{L}$ of a 1,1'-dioctadecyl-3,3,3',3'-tetramethylindodicarbocyanine perchlorate solution (Invitrogen Inc.) (1mg/mL in methanol). After chloroform was thoroughly removed by vacuum, phosphate buffered saline (PBS, 10mM, pH 8.1, 150mM $\mathrm{NaCl}$ ) was added and mixed. Details of the preparation, using polycarbonate membrane filters (Avestin Inc.) with pore diameter of $400 \mathrm{~nm}$ mounted in a mini-extruder (Avestin Inc.), can be found elsewhere (54).

\subsection{Methods of Preparation of the Support}

\subsubsection{Substrate Cleaning and Activation}

Silicon wafers $\mathrm{Si}(100)$ (ACM, France) cut into square strips of $2 \times 2 \mathrm{~cm}^{2}$ or thin microscope glass slides (see below) were used as substrates for spin-coating deposition. The square was cut into four pieces of $1 \mathrm{~cm}^{2}$ area for phospholipid 
reaction with the PMHS layer. To bond covalently the PMHS thin films to native oxide silica (thickness $\sim 2 \mathrm{~nm}$ ), the silicon wafers were first cleaned and activated using the previously described procedure with "piranha" solution $\mathrm{H}_{2} \mathrm{SO}_{4} / \mathrm{H}_{2} \mathrm{O}_{2}-30 \% \mathrm{w}(70 / 30 \mathrm{vol}) ; 90^{\circ} \mathrm{C} ; 30 \mathrm{~min}(55)$. Caution: piranha solution must be handled extremely carefully. For fluorescence adsorption measurements, the substrates were wafers or thin microscope glass slides (Menzel-Glazer, Germany) of $2.5 \times 6 \mathrm{~cm}^{2}$ submitted to the same treatment to bond PMHS. However, for protein adsorption to glass (without subsequent PMHS bonding), the substrate was previously treated with sulfochromic acid and rinsed carefully just before adsorption experiment.

\subsubsection{PMHS Films}

PMHS thin films were prepared at $22 \pm 1{ }^{\circ} \mathrm{C}$ by sol-gel polymerization of $\mathrm{DH}$ and $\mathrm{TH}$ as crosslinker. DH/TH 95/5 (mol\%) sol mixtures were deposited by spin-coating on freshly activated substrates according to the procedure (51, 52) summarized as follows. Trifluoromethanesulfonic acid $\mathrm{CF}_{3} \mathrm{SO}_{3} \mathrm{H}(1.0 \mathrm{M}$ in absolute ethanol $)$ was used as catalyst $(0.5 \mathrm{mmol} / \mathrm{mol}$ of monomers $)$. The mixture of monomers $(4.0 \mathrm{M}$ in EtOH; molar ratio $[\mathrm{EtOH}] /[\mathrm{Si}]=1)$ was polymerized with hydrolysis ratio $h=\left[\mathrm{H}_{2} \mathrm{O}\right] /[\mathrm{SiOEt}]=0.5$. The content of trifluoromethanesulfonic acid was not higher than $0.05 \%$ to control the kinetics of gelation of the liquid mixture. The resulting clear sols were allowed to age for $\sim 30$ minutes with magnetic stirring before spin-coating deposition. The freshly cleaned silicon wafer was purged $(2 \mathrm{~min})$ in the spin-coater (Spin150, SPS Europe) under a stream of nitrogen $(2 \mathrm{~L} / \mathrm{min})$ to avoid air moisture. For all samples, the speed of rotation was $4000 \mathrm{rpm}$ (spin acceleration $2000 \mathrm{rpm} / \mathrm{s}$ ) and the rotation time $30 \mathrm{~s}$. The samples were finally cured at $110^{\circ} \mathrm{C}$ in an oven for 15 minutes. This procedure gave layers of reproducible homogeneity and thickness as verified by electron microscopy and infrared analysis.

\subsubsection{Grafting PMHS with Phospholipid To Afford PL-PMHS}

After spin-coating PMHS layer onto pieces of oxidized silicon wafer, the hydrosilylation reaction between the dilinoleoyl phospholipid (PL) and the PMHS $\mathrm{SiH}$ functional group was performed in air by casting solutions $(20 \mathrm{mg}$ PL in $1 \mathrm{~mL}$ of toluene $(25.5 \mathrm{mM})$, with an additional $2 \mu \mathrm{L}$ of the xylene solution of the platinum divinyltetramethyldisiloxane complex, Karstedt's catalyst) or by immersion of the plates in the PL solution. The reaction was then allowed to proceed at room temperature $\left(\sim 20^{\circ} \mathrm{C}\right)$ or $40^{\circ} \mathrm{C}$, before the sample was rinsed with toluene/chloroform mixtures ranging from $100 \%$ to $0 \%$ to remove any physisorbed material, and finally dried under a stream of nitrogen for 5 minutes. Then the samples were immersed in water for two hours and finally re-dried. Transmission infrared (IR) absorption spectra of the $1 \mu \mathrm{m}$ thick films before and after hydrosilylation were used to ascertain the reaction yield after solvent and water rinsing, XPS spectra was used for thick and very thin films. The air captive 
bubble contact angle in water was finally measured in order to characterize the sample surface hydrophilicity. We used the notation PL-PMHS $(x \mathrm{~nm})$ to signify that PL reaction occurred on an initial PMHS layer of thickness $x \mathrm{~nm}$.

\subsubsection{Synthesis of Monoethoxysilane Bearing Alexa. Grafting on PL-PMHS}

To a solution of Alexa Fluor ${ }^{\circledR} 594$ succinimidyl ester $(12.2 \mathrm{nmol})$ in dry ethanol $(100 \mu \mathrm{L})$ under an argon atmosphere, was added 3-(ethoxydimethylsilyl)propyl amine $(12.2 \mathrm{nmol})$. The reaction mixture was vigorously stirred for two hours at room temperature. The resulted mixture was then divided into ten parts. The solvent was evaporated under reduced pressure and the product alexa-monoethoxysilane thus obtained was used without further purification. HRMS (Q-Tof) : Calcd for $\mathrm{C}_{35} \mathrm{H}_{35} \mathrm{~N}_{3} \mathrm{O}_{10} \mathrm{~S}_{2} 721.1745$ ( $\mathrm{M}^{-}-\mathrm{C}_{4} \mathrm{H}_{11} \mathrm{SiO}$ ); found: 721.1764 .

PL-PMHS functionalization: Each part of the divided alexamonoethoxysilane $(\sim 1 \mathrm{nmol})$ was dissolved in a mixture of toluene/dry ethanol $(700 \mu \mathrm{L} / 300 \mu \mathrm{L})$. The PL-PMHS coated surfaces were then soaked in the solution for one hour. The substrates were further rinsed with ethanol, dried under a stream of argon, then kept overnight in Milli-Q water in order to remove any trace of physically adsorbed alexa before characterisation by confocal microscopy.

PL-PMHS passivation with hexamethyldisilazane (HMDS): The substrate with a PL-PMHS layer was dried under a stream of argon and treated with a solution of $95-5 \%$ (vol.) of dry toluene-HMDS for $30 \mathrm{~min}$ at room temperature. After rinsing with toluene, and drying under a stream of argon, the substrate was soaked in alexa-monoethoxysilane solution as described above.

\subsection{Techniques of Characterization of the Support}

\subsubsection{X-ray Photoelectron Spectroscopy (XPS)}

The surface elemental composition of the PMHS and PL-PMHS surfaces were analysed by XPS, as previously described (53). The spectra were obtained by means of a spectrophotometer (ESCALAB 250, Thermo Electron, UK) equipped with a monochromatic $\mathrm{Al} \mathrm{K \alpha}(1486.6 \mathrm{eV})$ radiation source. The acceleration tension and power of the X-ray source were $15 \mathrm{kV}$ and $100 \mathrm{~W}$, respectively. Survey scans $(0-1350 \mathrm{eV})$ at low resolution were performed to identify the constitutive elements. High resolution $\mathrm{C}_{1 \mathrm{~s}}, \mathrm{Si}_{2 \mathrm{p}}, \mathrm{O}_{1 \mathrm{~s}}, \mathrm{~N}_{1 \mathrm{~s}}$ and $\mathrm{P}_{2 \mathrm{p}}$ spectra were recorded to obtain more detailed information on the nature of the surface.

\subsubsection{Captive Air Bubble Contact Angle Measurements in Water}

Air captive bubble contact angles in water were measured (GBX - Digidrop, Romans, France) by applying an air bubble of about $25 \mu \mathrm{L}$ to the surface. The contact angle through air was calculated using computerized image analysis. The

682

In Proteins at Interfaces III State of the Art; Horbett, T., et al.; ACS Symposium Series; American Chemical Society: Washington, DC, 2012. 
data dicussed are relative to the complement angle to $180^{\circ}$ through the liquid as generally defined (56), in opposition to the angle through air as used in a previous work (53).

\subsubsection{AFM and SEM}

Atomic Force Microscopy (AFM) experiments were performed using a Dimension 3100 microscope equipped with a Nanoscope IIIa controller system (Digital Instruments, Veeco Metrology Group). AFM images were obtained by scanning in tapping mode in water or under air ambient conditions using silicon SPM probes (stiffness $k \approx 2 \mathrm{~N} / \mathrm{m}$, resonance frequency of $67 \mathrm{kHz}$, pointeprobeplus, Nanosensors). The root mean square average roughness $\left(R_{q}\right)$ was analyzed by the Nanoscope software (version 5.31r1). Scanning electron microscopy (SEM) pictures were obtained with a Hitachi S4800 instrument. The MeX software (version 5.1) was used for the construction of the 3D SEM image and z-profile $( \pm 10 \mathrm{~nm})$ from differently tilted SEM images.

\subsection{Adsorption: Determination of Interfacial Concentration}

The experiments were performed at $\mathrm{T}=19^{\circ} \mathrm{C}$ in a slit flow cell of thickness 63 or $105 \mu \mathrm{m}$ and flow rate corresponding to wall shear rate $1000 \mathrm{~s}^{-1}$. Entrance design leads to a sharp transition between the flows of buffer and solution. Confocal measurements were performed at $3 \mathrm{~cm}$ from the slit entrance.

The interfacial concentration was evaluated as follows: the fluorescence

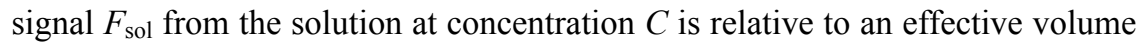
$V$ while the signal $F_{\text {surf }}$ at the surface concerns the interfacial concentration $\Gamma$ over area $A . F_{\text {surf }} \propto \Gamma A$ and $F_{\text {sol }} \propto C V$ therefore $\Gamma=(V / A)\left(F_{\text {surf }} / F_{\text {sol }}\right) C$. In a previous paper (57) the order of magnitude of $V / A$ was estimated from the focus radius for $A$ and $1 \mu \mathrm{m}^{3}$ taken as the confocal volume $V$. We proposed recently (53) the experimental determination of $V / A$ and we will recall shortly the argument. The normal scanning of the laser beam through a flat fluorescent interface leads to a peak $F_{\mathrm{i}}(y)$ which can be viewed as the convolution of the laser beam with a Dirac function (Figure 2).

Considering the same beam scanning in fluorescent solution viewed as a contiguous series of thin slabs treated like Dirac functions, and summing all contributions when focusing at one point in solution, it is deduced that $V / A$ is the area under the peak of the interface normalized to its maximal value. The width $\mathrm{w}_{\mathrm{D}}=V / A$ was in the range $2-2.5 \mu \mathrm{m}$.

$$
\frac{V}{A}=w_{D}=\int_{-\infty}^{+\infty} \frac{F_{i}(y)}{F_{i}(0)} d y
$$

The presence of solution (step function at interface) leads to a contribution when focusing at interface which is half the signal in bulk solution. We used then

683

In Proteins at Interfaces III State of the Art; Horbett, T., et al.; 
as surface signal $F_{\text {surf }}$ the raw signal minus half the solution signal. This correction was negligible when a strong adsorption occurred at small solution concentrations.

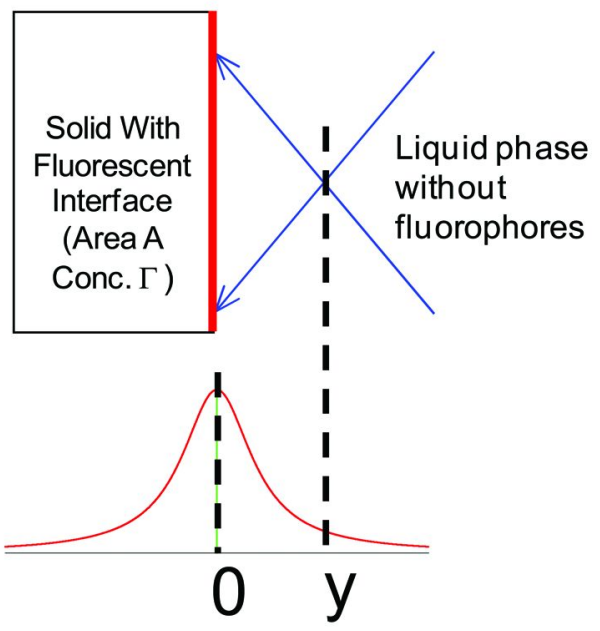

Figure 2. (top) Scheme of focused laser beam at some distance from an interface occupied by fluorescent molecules. No fluorescent molecules in solution. (bottom) Resulting peak $F_{i}(y)$ from normal scanning to the interface. Adapted with permission from ref. (53). Copyright 2011 American Chemical Society.

\section{Results and Discussion}

\subsection{Material Characterization}

The two interfaces of PMHS and PL-PMHS were examined by AFM, air bubble contact angle and SEM (Figure 3).

The PMHS layer presented always a small roughness of some tenths of nanometer and a hydrophobic character with a $90^{\circ}$ air bubble contact angle. Reaction with phospholipid (PL) induced the creation of $\sim 2 \mu \mathrm{m}$ large grooves on thick $(\sim 1 \mu \mathrm{m})$ PMHS, with a depth of $100 \mathrm{~nm}$. The reaction led to a very hydrophilic material as we observed a contact angle close to $0^{\circ}$ and rolling bubbles. SEM exhibited the swelling of PMHS under reaction with PL, as previously observed under reaction with linear olefins (51). The grooves and generally the structures observed after reaction with PL were mainly attributed to the reticulation induced by side reaction with water. Such reaction was suggested by $\mathrm{Si}_{2 \mathrm{p}}$ XPS spectra which exhibited an unexpected increase of the component of silicon surrounded by three oxygens under reaction of PMHS with PL (Figure 4). In addition, streaming potential showed an interfacial behavior consistent with the presence of silanols (53).

With smaller PMHS thicknesses (10-200 nm) we did not observe such large grooves, the roughness $R_{q}$ being of the order of a few nanometers with a minimum less than $1 \mathrm{~nm}$ for PMHS thickness of $20 \mathrm{~nm}$ (54). 

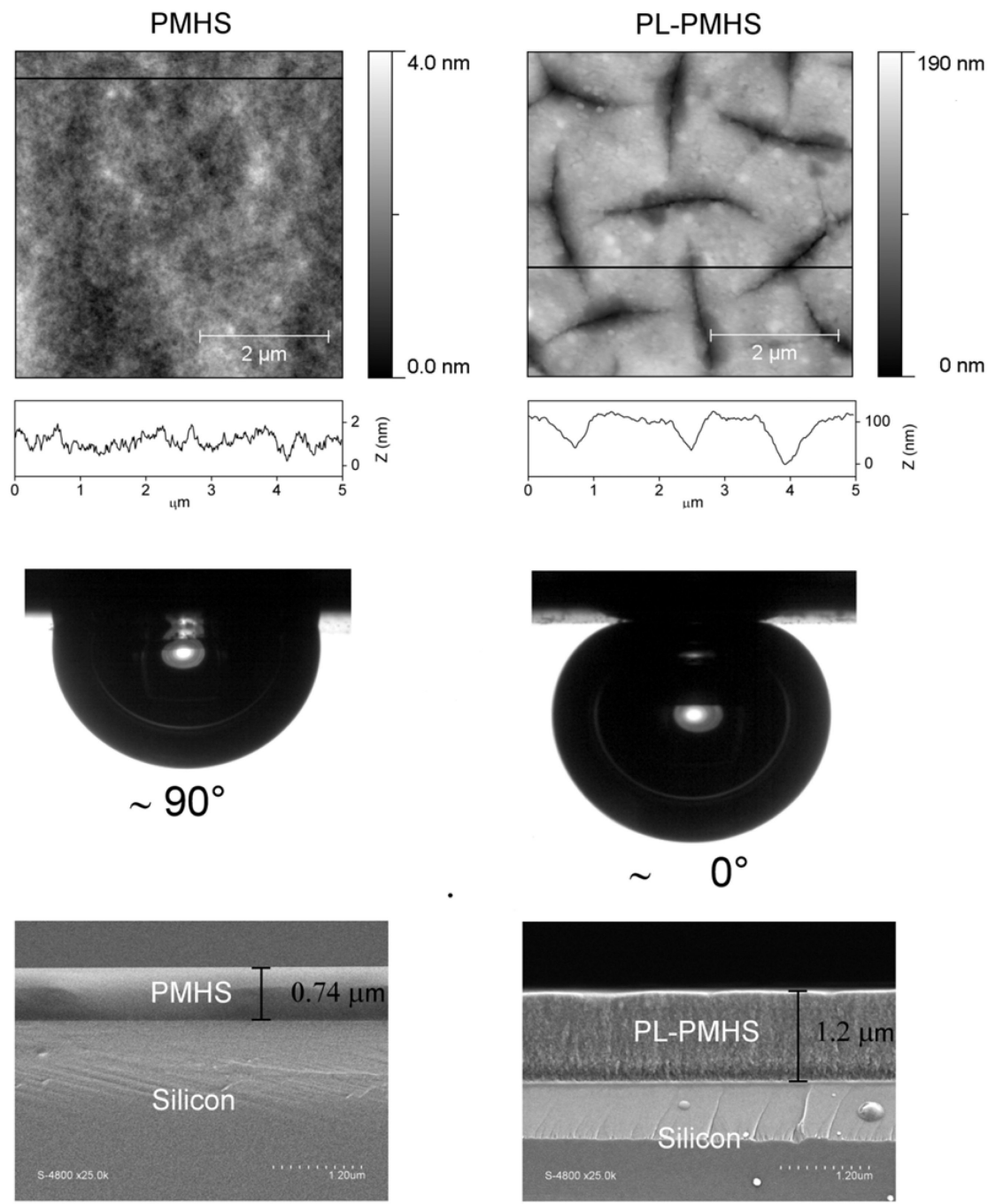

Figure 3. Comparison of PMHS (left) and PL-PMHS (right) analysis by-from top to bottom - atomic force microscopy (AFM; $5 \mu \mathrm{m} \times 5 \mu \mathrm{m})$, captive air bubble contact angle and scanning electron microscopy (SEM). Adapted with permission from ref. (53). Copyright 2011 American Chemical Society.

\subsection{Protein Adsorption}

The adsorption of several proteins was checked on PL-PMHS(1 $\mu \mathrm{m})$ surfaces prepared at room temperature (Figure 5). Very low interfacial concentrations, clearly below $1 \mathrm{ng} \mathrm{cm}^{-2}$, were obtained for all proteins, except for the fibrinogen at $100 \mu \mathrm{g} / \mathrm{mL}$. BSA presented the peculiar behavior of slow desorption over $10 \mathrm{~min}$ while rinsing with buffer.

685

In Proteins at Interfaces III State of the Art; Horbett, T., et al.;

ACS Symposium Series; American Chemical Society: Washington, DC, 2012. 


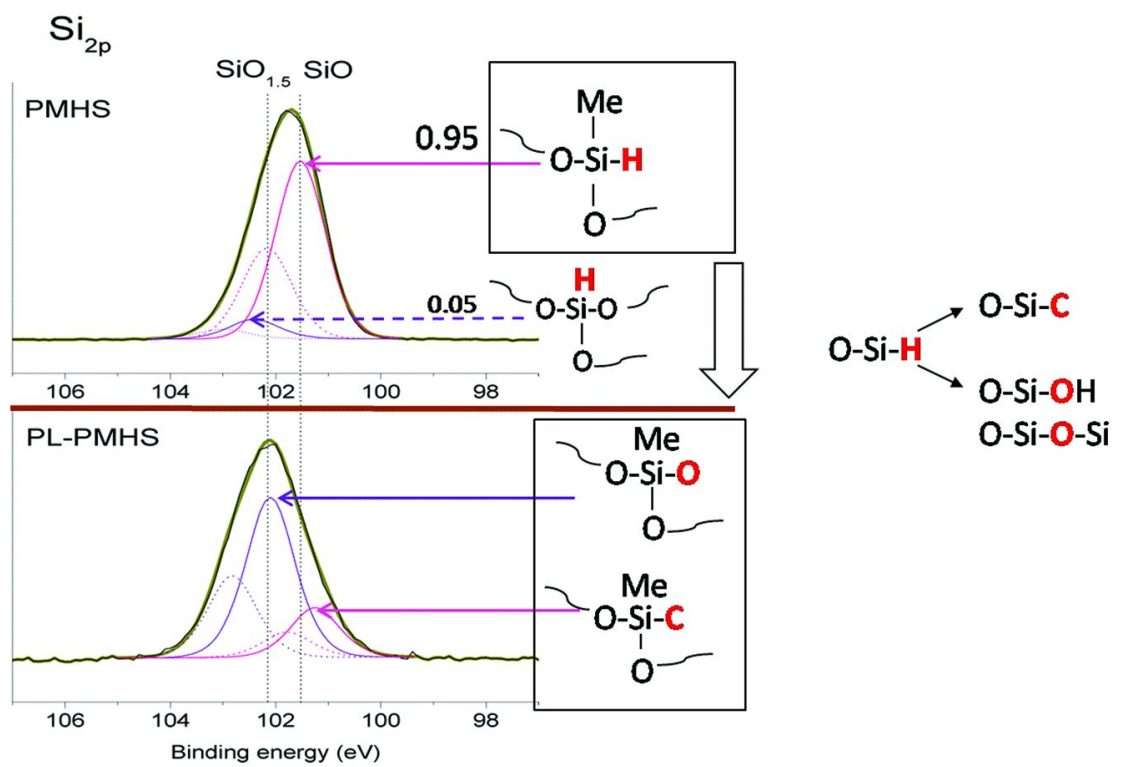

Figure 4. XPS spectra of $\mathrm{Si}_{2 p}$ for PMHS (top) and PL-PMHS (bottom).

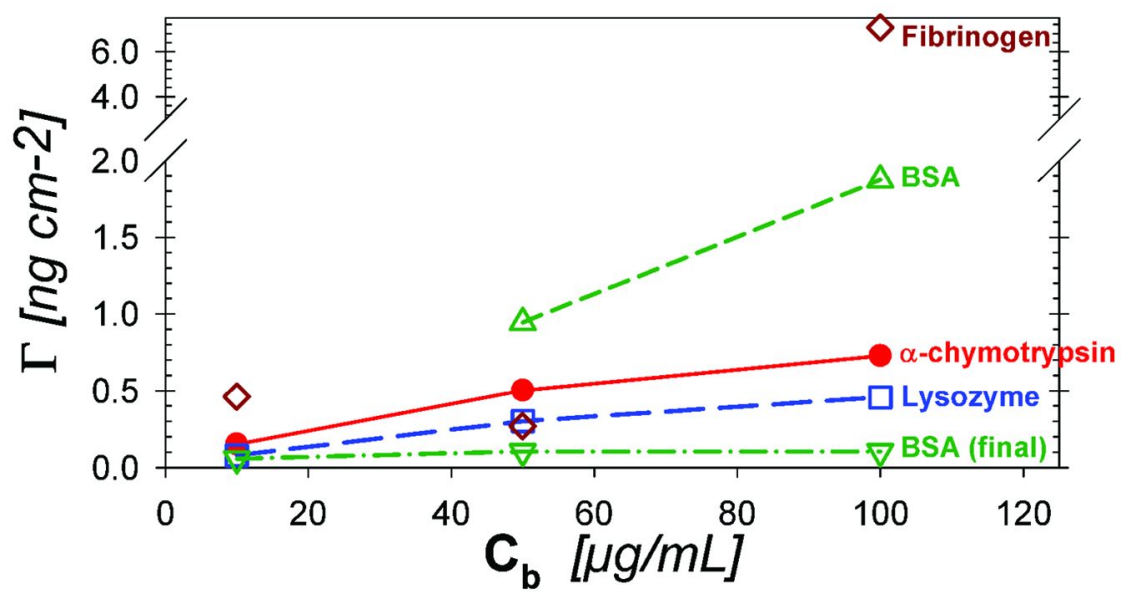

Figure 5. Interfacial concentration on PL-PMHS(1 $\mu \mathrm{m})$ as a function of protein solution concentration. Higher values for BSA (1-2 $\left.\mathrm{ng} \mathrm{cm}^{-2}\right)$ correspond to the beginning of rinsing.

686

In Proteins at Interfaces III State of the Art; Horbett, T., et al.; ACS Symposium Series; American Chemical Society: Washington, DC, 2012. 
The same kind of behavior was observed with interfaces prepared from much smaller thicknesses of the initial PMHS network (Figure 6). The mean values were for avidin $(5 \mu \mathrm{g} / \mathrm{mL}) \Gamma=0.1 \pm 0.9 \mathrm{ng} \mathrm{cm}^{-2}$ on PL-PMHS $(180 \mathrm{~nm})$ and $(10 \mu \mathrm{g} / \mathrm{mL})$ $1.2 \pm 0.9 \mathrm{ng} \mathrm{cm}^{-2}$ on PL-PMHS(7 nm); for BSA $(10 \mu \mathrm{g} / \mathrm{mL}), \Gamma=0.5 \pm 0.3 \mathrm{ng}$ $\mathrm{cm}^{-2}$ on PL-PMHS(20 nm). Taking into account the transport contribution in the analysis of the initial kinetics $(58,59)$ on glass, we obtained $k_{a}=0.97 \times 10^{-4} \mathrm{~cm}$ $\mathrm{s}^{-1}$ for avidin from the initial raw kinetic constant $k=0.74 \times 10^{-4} \mathrm{~cm} \mathrm{~s}^{-1}$, and 0.060 $\times 10^{-4} \mathrm{~cm} \mathrm{~s}^{-1}$ for BSA where transport contribution was negligible. Indeed, with $D \approx 6 \times 10^{-7} \mathrm{~cm}^{2} \mathrm{~s}^{-1}, x=3 \mathrm{~cm}$ and wall shear rate $1000 \mathrm{~s}^{-1}$, the transport limited constant $k_{L e v}$ is $2.6510^{-4} \mathrm{~cm} \mathrm{~s}^{-1}$ and $u=k / k_{L e v}=0.28$ for avidin and 0.022 for BSA. The $k_{a}$, value, illustrated by the graphical interpolation in Figure 7, is determined by applying accurate approximations $(58,59)$, as the two parameters expression $k_{a}=k(\mathrm{~b} u+1) /((u-1)(\mathrm{a} u-1))$, where $\mathrm{a}=0.452, \mathrm{~b}=-0.625(58)$.

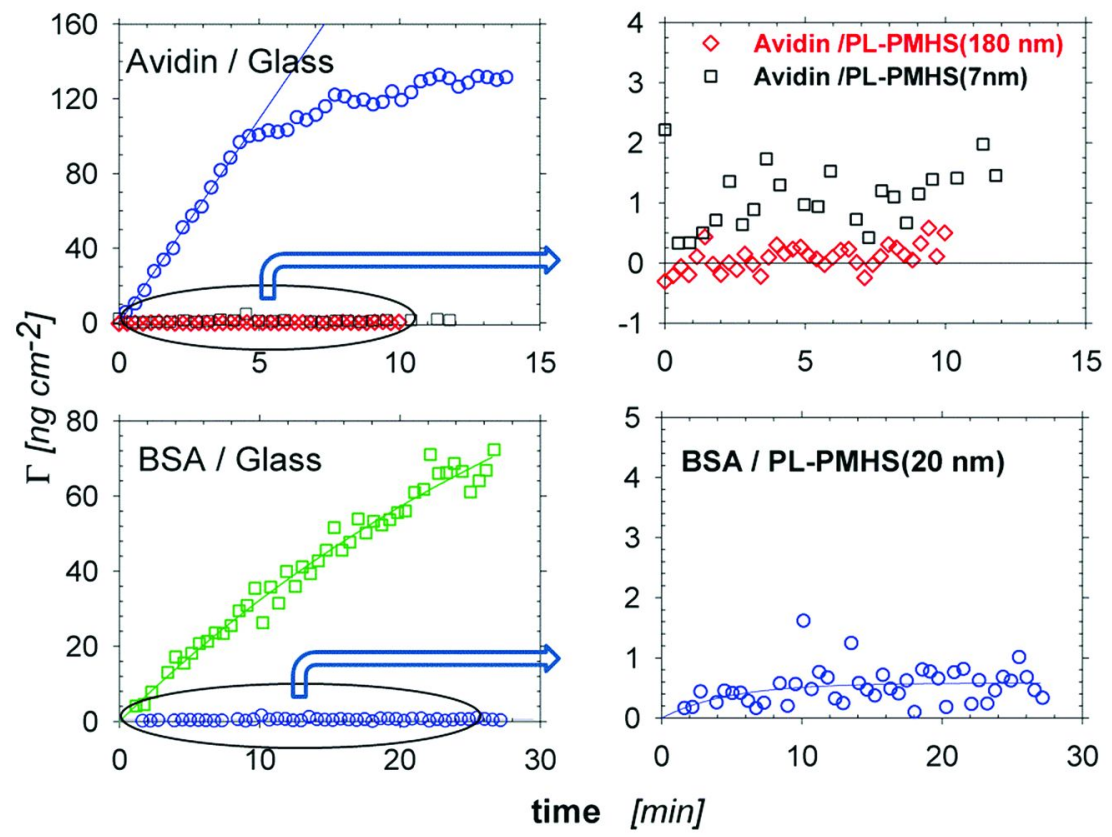

Figure 6. Passivation of PL-PMHS interfaces with respect to BSA and avidin adsorption, compared to glass. Enlargement of scales (graphs on the right) allows to show the order of magnitude of the interfacial concentration. Adapted with permission from ref. (54). Copyright 2012 Elsevier. 


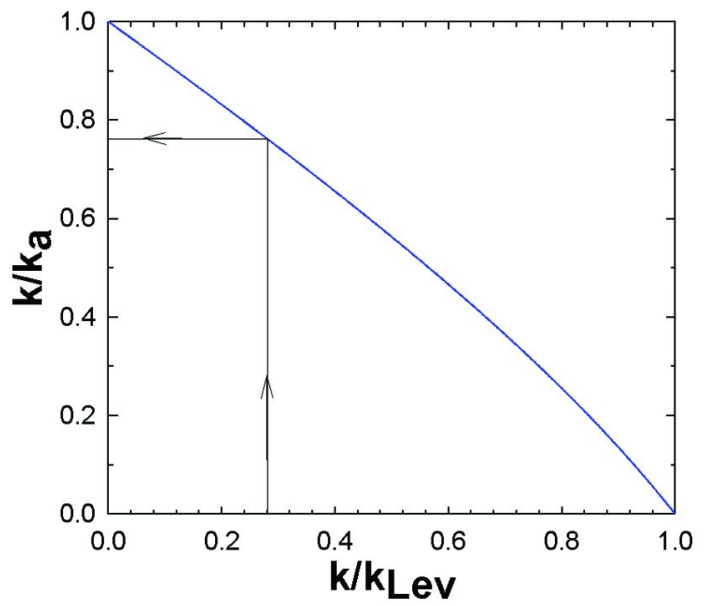

Figure 7. Graphical determination of adsorption kinetic constant $k_{a}$ from raw kinetic constant $k$ and transport-limited constant $k_{\text {Lev }}=0.538\left(D^{2} \gamma / x\right)^{1 / 3}$.

\subsection{Liposome Adsorption/Spreading}

Adsorption of labeled (DiD) liposomes of L- $\alpha$-Phosphatidylcholine (diameter $400 \mathrm{~nm}$ ) was measured by scanning confocal fluorescence as for the proteins. Based on an average area per head of $0.5 \mathrm{~nm}^{2}$ or diameter per head of $0.8 \mathrm{~nm}$, the adsorption at different interfaces (Figure 8) illustrates the neutral nature of the PL-PMHS interface as no adsorption/spreading was observed, contrary to the other interfaces of glass and PMHS.

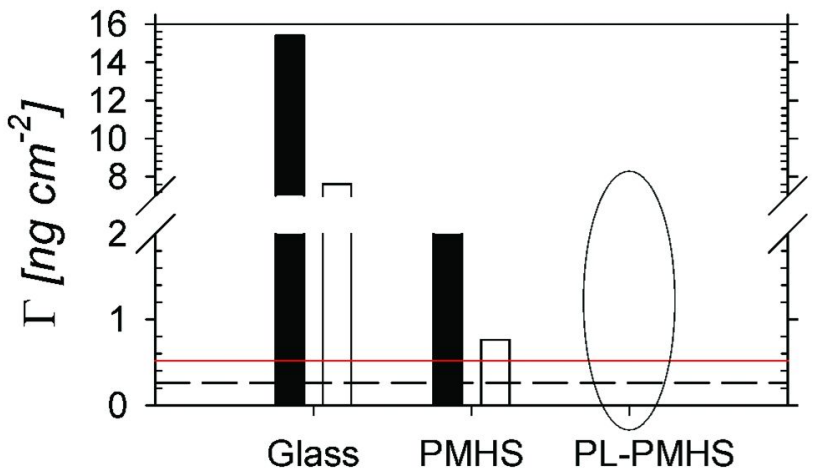

Figure 8. Adsorption/spreading of labeled liposomes on piranha treated glass, PMHS and PL-PMHS. After (full bar) one and (empty bar) a few rinsings. Horizontal lines correspond to estimated (dashed line) monolayer and (full line) bilayer coverage. Adapted with permission from ref. (54). Copyright 2012 Elsevier.

688

In Proteins at Interfaces III State of the Art; Horbett, T., et al.; ACS Symposium Series; American Chemical Society: Washington, DC, 2012. 


\subsection{Functionalization of PL-PMHS Surface}

The interfacial silanol groups revealed by the XPS analysis after PL reaction with PMHS could be available for subsequent reaction. Their presence was checked by reaction of a monoethoxy silane coupling agent bearing alexa as fluorescent probe (53). The high fluorescence signal confirmed the possibilities of chemical functionalization at such surfaces, whereas pretreatment of PL-PMHS with hexamethyldisilazane (HMDS) led to no coupling reaction as the silanols were neutralized by bulky trimethylsilyl groups.

Quantitative analyze of fluorescence led to a mean degree of functionalization of PL-PMHS layer of $3.0 \times 10^{-2} \mathrm{~nm}^{-2}$. Therefore an order of magnitude of the mean distance between sites on the assumed flat surface was estimated to be 5.7 $\mathrm{nm}$. Such sites can be provided with amino groups available for amide junctions (54).

\section{Conclusion}

Polymethylhydrosiloxane anchored on an activated oxidized silicon wafer or glass can be deposited as a thick $(\sim 1 \mu \mathrm{m})$ or very thin $(7-180 \mathrm{~nm})$ film and provided with covalently bonded phospholipids bearing a phosphorylcholine head. A $20 \mathrm{~nm}$ thin PMHS layer led to very flat surfaces with roughness less than $1 \mathrm{~nm}$, whereas thick PMHS layers led to final PL-PMHS surface with large grooves of depth 100 nm.

Whatever the initial PMHS thickness, the resulting PL-PMHS interface was protein-repellent at neutral $\mathrm{pH}$ in phosphate saline buffer with side reaction silanols available for appropriate functionalization. The repellent character was also observed with $400 \mathrm{~nm}$ L- $\alpha$-Phosphatidylcholine liposomes. Therefore adequate functionalization could help to fix specific cells to the interface. However, the control of the pertinent character of softness in cell spreading (60), through the ratio $\mathrm{DH} / \mathrm{TH}$ in the synthesis of the PMHS films would require a better control of water in subsequent grafting.

Finally the protein-repellent interface can be easily provided with amine functional group. Therefore such protein-repellent interface can be useful in the biomedical domain, e.g. for biosensors, biomaterials and cell culture, by reducing strongly the non-specific adsorption, on the one hand, and offering in addition the possibilities for grafting desired functions, on the other hand. Moreover the covalent coverage with phospholipids and the silanol sites for further functionalization are generated simultaneously in a one step process.

Let us note also that the strategy of first anchoring a PMHS network opens the possibility to graft thereafter different compositions of phospholipids, provided they possess at least one double bond in their fatty chains. With respect to other surfaces prepared with covalent bonding of phospholipids the present method provides surfaces without carbon - carbon double bonds and therefore diminishes strongly the probability of autoxidation. 


\section{Acknowledgments}

This work was especially supported by FP7 European grant NMP-214538 (BISNES project; Coord. D. Nicolau). We are grateful to M. Ramonda (LMCP, UM2) for the AFM pictures, to D. Cot (IEM, UM2) for SEM pictures, and to F. Pichot (UM2) for access to clean room and ellipsometry.

\section{References}

1. Ogi, H.; Fukunishi, Y.; Nagai, H.; Okamoto, K.; Hirao, M.; Nishiyama, M. Biosens. Bioelectron. 2009, 24, 3148-3152.

2. Holmberg, M.; Hou, X. L. Colloids Surf., B 2011, 84, 71-75.

3. Vermette, P.; Meagher, L. Colloids Surf., B 2003, 28, 153-198.

4. Yan, F.; Dejardin, P.; Mulvihill, J. N.; Cazenave, J. P.; Crost, T.; Thomas, M.; Pusineri, C. J. Biomater. Sci., Polym. Ed. 1992, 3, 389-402.

5. Lee, J.; Kopecek, J.; Andrade, J. J. Biomed. Mater. Res. 1989, 23, 351-368.

6. Wu, Y. J.; Timmons, R. B.; Jen, J. S.; Molock, F. E. Colloids Surf., B 2000, $18,235-248$.

7. Maste, M. C. L.; van Velthoven, A. P. C. M.; Norde, W.; Lyklema, J. Colloids Surf., A 1994, 83, 255-260.

8. Archambault, J. G.; Brash, J. L. Colloids Surf., B 2004, 39, 9-16.

9. Du, Y. J.; Brash, J. L. J. Appl. Polym. Sci. 2003, 90, 594-607.

10. Cecchet, F.; De Meersman, B.; Demoustier-Champagne, S.; Nysten, B.; Jonas, A. M. Langmuir 2006, 22, 1173-1181.

11. Unsworth, L. D.; Sheardown, H.; Brash, J. L. Langmuir 2008, 24, 1924-1929.

12. Tan, J.; McClung, W. G.; Brash, J. L. J. Biomed. Mater. Res., Part A 2008, $85 A, 873-880$.

13. Tan, J.; Brash, J. L. J. Appl. Polym. Sci. 2008, 108, 1617-1628.

14. Holmberg, M.; Hou, X. L. Langmuir 2010, 26, 938-942.

15. Ionov, L.; Synytska, A.; Kaul, E.; Diez, S. Biomacromolecules 2010, 11, 233-237.

16. Trmcic-Cvitas, J.; Hasan, E.; Ramstedt, M.; Li, X.; Cooper, M. A.; Abell, C.; Huck, W. T. S.; Gautrot, J. E. Biomacromolecules 2009, 10, 2885-2894.

17. Su, Y. L.; Li, C. React. Funct. Polym. 2008, 68, 161-168.

18. Yang, W.; Xue, H.; Li, W.; Zhang, J. L.; Jiang, S. Y. Langmuir 2009, 25, 11911-11916.

19. Liu, P. S.; Chen, Q.; Liu, X.; Yuan, B.; Wu, S. S.; Shen, J.; Lin, S. C. Biomacromolecules 2009, 10, 2809-2816.

20. Prime, K.; Whitesides, G. Science 1991, 252, 1164.

21. Li, L. Y.; Chen, S. F.; Jiang, S. Y. J. Biomater. Sci., Polym. Ed. 2007, 18, $1415-1427$.

22. Dormidontova, E. E. Macromolecules 2002, 35, 987-1001.

23. Ostuni, E.; Chapman, R. G.; Holmlin, R. E.; Takayama, S.; Whitesides, G. M. Langmuir 2001, 17, 5605-5620.

24. Zwaal, R. Nature 1977, 268, 358.

25. Chapman, D. Langmuir 1993, 9, 39-45. 
26. Hall, B.; Bird, R. L.; Chapman, D. Angew. Makromol. Chem. 1989, 166, 169-178.

27. Leaver, J.; Alonso, A.; Durrani, A. A.; Chapman, D. Biochim. Biophys. Acta 1983, 732, 210-218.

28. Albrecht, O.; Johnston, D. S.; Villaverde, C.; Chapman, D. Biochim. Biophys. Acta 1982, 687, 165-169.

29. Johnston, D. S.; Sanghera, S.; Pons, M.; Chapman, D. Biochim. Biophys. Acta 1980, 602, 57-69.

30. Marra, K. G.; Winger, T. M.; Hanson, S. R.; Chaikof, E. L. Macromolecules 1997, 30, 6483-6488.

31. Kohler, A. S.; Parks, P. J.; Mooradian, D. L.; Rao, G. H. R.; Furcht, L. T. J. Biomed. Mater. Res. 1996, 32, 237-242.

32. Yang, W.; Chen, S. F.; Cheng, G.; Vaisocherova, H.; Xue, H.; Li, W.; Zhang, J. L.; Jiang, S. Y. Langmuir 2008, 24, 9211-9214.

33. Zhang, Z.; Chen, S. F.; Jiang, S. Y. Biomacromolecules 2006, 7, 3311-3315.

34. Ishihara, K.; Takai, M. J. R. Soc. Interface 2009, 6, S279-S291.

35. Ishihara, K.; Nomura, H.; Mihara, T.; Kurita, K.; Iwasaki, Y.; Nakabayashi, N. J. Biomed. Mater. Res. 1998, 39, 323-330.

36. Sheng, Q.; Schulten, K.; Pidgeon, C. J. Phys. Chem. 1995, 99, 11018-11027.

37. Goda, T.; Watanabe, J.; Takai, M.; Ishihara, K. Polymer 2006, 47, 1390-1396.

38. Ishihara, K.; Ziats, N. P.; Tierney, B. P.; Nakabayashi, N.; Anderson, J. M. J. Biomed. Mater. Res. 1991, 25, 1397-1407.

39. Ishihara, K.; Takayama, R.; Nakabayashi, N.; Fukumoto, K.; Aoki, J. Biomaterials 1992, 13, 235-239.

40. Furuzono, T.; Ishihara, K.; Nakabayashi, N.; Tamada, Y. Biomaterials 2000 , 21, 327-333.

41. Konno, T.; Kurita, K.; Iwasaki, Y.; Nakabayashi, N.; Ishihara, K. Biomaterials 2001, 22, 1883-1889.

42. Jang, K.; Sato, K.; Mawatari, K.; Konno, T.; Ishihara, K.; Kitamori, T. Biomaterials 2009, 30, 1413-1420.

43. Xu, Y.; Takai, M.; Ishihara, K. Biomacromolecules 2009, 10, 267-274.

44. Goda, T.; Konno, T.; Takai, M.; Moro, T.; Ishihara, K. Biomaterials 2006, 27, 5151-5160.

45. Chen, M.; Briscoe, W. H.; Armes, S. P.; Klein, J. Science 2009, 323, 1698-1701.

46. Cheng, G.; Li, G. Z.; Xue, H.; Chen, S. F.; Bryers, J. D.; Jiang, S. Y. Biomaterials 2009, 30, 5234-5240.

47. Feng, W.; Brash, J. L.; Zhu, S. P. Biomaterials 2006, 27, 847-855.

48. Ye, S. H.; Johnson, C. A.; Woolley, J. R.; Murata, H.; Gamble, L. J.; Ishihara, K.; Wagner, W. R. Colloids Surf., B 2010, 79, 357-364.

49. Reisch, A.; Voegel, J. C.; Decher, G.; Schaaf, P.; Mesini, P. J. Macromol. Rapid Commun. 2007, 28, 2217-2223.

50. Tegoulia, V. A.; Cooper, S. L. J. Biomed. Mater. Res. 2000, 50, 291-301.

51. Thami, T.; Nasr, G.; Bestal, H.; van der Lee, A.; Bresson, B. J. Polym. Sci., Part A: Polym. Chem. 2008, 46, 3546-3562. 
52. Nasr, G.; Bestal, H.; Barboiu, M.; Bresson, B.; Thami, T. J. Appl. Polym. Sci. 2009, 111, 2785-2797.

53. Ferez, L.; Thami, T.; Akpalo, E.; Flaud, V.; Tauk, L.; Janot, J. M.; Dejardin, P. Langmuir 2011, 27, 11536-11544.

54. Tauk, L.; Thami, T.FerezL.; Kocer, A.; Janot, J.-M.; Dejardin, P. Colloids Surf., B 2012, 101, 189-195.

55. Thami, T.; Bresson, B.; Fretigny, C. J. Appl. Polym. Sci. 2007, 104, 1504-1516.

56. Hong, S. J.; Chang, F. M.; Chou, T. H.; Chan, S. H.; Sheng, Y. J.; Tsao, H. K. Langmuir 2011, 27, 6890-6896.

57. Janot, J.-M.; Boissiere, M.; Thami, T.; Tronel-Peyroz, E.; Helassa, N.; Noinville, S.; Quiquampoix, H.; Staunton, S.; Dejardin, P. Biomacromolecules 2010, 11, 1661-1666.

58. Dejardin, P.; Vasina, E. N. Colloids Surf., B 2004, 33, 121-127.

59. Noinville, S.; Vidic, J.; Dejardin, P. Colloids Surf., B 2010, 76, 112-116.

60. Ren, K. F.; Fourel, L.; Rouviere, C. G.; Albiges-Rizo, C.; Picart, C. Acta Biomater. 2010, 6, 4238-4248. 